\title{
Research on Strategies of Optimizing Industrial Structure in Hebei Province
}

\author{
Zhihao $\mathrm{Su}$ \\ Langfang Teacher's College \\ LangFang HeBei China \\ e-mail:Heavencolour_00@163.com
}

\author{
Yajuan Chen \\ Langfang Teacher's College \\ Langfang HeBei China \\ e-mail:2463676511@qq.com
}

\begin{abstract}
By analyzing the structure proportion of output data and three industries of Hebei province in 2012 compared with that of China and Guangdong, Jiangsu, Shandong province, this paper aims to find the major problems exist in current Hebei industrial structure, by means of data analysis and theoretical research, as well as to put forward some suggestions of optimizing the industrial structure in Hebei province in accordance with these problems.
\end{abstract}

Keywords-optimize; industrial structure; adjust

\section{INTRODUCTION}

China there are some people who studied the industrial structure in hebei province, but nearly two years of the study is less, this paper mainly on the basis of previous studies by nearly two years of the industrial structure in hebei province data compared to the rest of the provinces of hebei province industrial structure still need to be optimized and adjusted from several aspects. Of course, some specific content late also need further scrutiny.

Since China's the reform and opening policy in 1978, the economic construction has received a spurt of progress. However, with the rapid development of economy and the convergence with international market, the development of Chinese industrial structure can be divided into two periods: the first period is from 1978 to 1985 which is the high-speed development period of Chinese industrial structure recovery, during which the industrial structure proportion changes from 28.19: $48.88: 23.93$ in 1978 to $28.44: 42.89: 28.67$ in 1985 . It has gained certain improvement but the change is not obvious. The second period is from 1986 until now, the improvement period in which the structure proportion is adjusted from 27.15:43.72:29.13 to 10.87:46.86:42.97 in 2010. In this period, the primary industry has experienced a large decrease, and the second industry almost remains stable while the tertiary industry has a large increase. Under the circumstance of national industrial structure adjustment, the industrial structure in Hebei province also changes a lot.

Hebei province is located in the northeast of China, surrounding the capital Beijing, east to Tianjin and right beside Bohai, with 11 provincial governed cities, 23 county-level city, 108 counties, 6 autonomous counties and 35 municipal districts. Hebei province possesses a superior location and rich resources. With the development of national economy and a process of 35 years' reform and opening, the current situation of industrial structure in Hebei province is as follows:

\section{CURRENT SITUATION OF INDUSTRIAL STRUCTURE IN HEBEI PROVINCE}

\section{A. Analysis on output value structure}

In 2012, the total output value of Hebei province reached 2657.6 billion yuan, achieving a $9.6 \%$ growth compared with that of 2011 calculated by comparable worth, among which the added value of primary industry was 318.67 billion yuan, with an increase of $4.0 \%$, the added value of second industry was 1400.10 billion yuan, with an increase of $11.5 \%$ and the added value of tertiary industry was 938.73 billion yuan, with an increase of $8.4 \%$. The proportion of the three industries in Hebei province was 12.0: 52.7: 35.3 while the proportion of tertiary industry increased by $0.7 \%$ compared with 2011 . Firstly these data have show that Hebei's industrial structure is developing in a rational direction. In 2012, the national GDP was 51932.2 yuan, and calculated by comparable worth, it had an increase of $7.8 \%$ compared with 2011, among which the added value of primary industry was 5237.7 billion yuan, with an increase of $4.5 \%$, the added value of second industry was 23531.9 billion yuan, with an increase of $8.1 \%$ and the added value of tertiary industry was 23162.6 billion yuan, with an increase of $8.1 \%$. In 2012, one of China's top three provinces with strong economic level Guangdong province achieved a total output value of 5706.792 billion yuan. If calculated by comparable worth, it had an increase of $8.2 \%$ compared with 2011 , among which the added value of primary industry was 284.891 billion yuan, with an increase of $3.9 \%$, he added value of second industry was 2782.53 billion yuan, with an increase of $7.6 \%$ and the added value of tertiary industry was 2639.371 billion yuan, with an increase of 9.2. The proportion of the three industries was 5.0:48.8:46.2. In 2012, the total output value of Jiangsu province reached 5405.82 billion yuan, achieving a $10.1 \%$ growth compared with that of 2011 calculated by comparable worth, among which the added value of primary industry was 341.83 billion yuan, with an increase of $4.6 \%$, the added value of second industry was 2712.19 billion yuan, with an increase of $11.0 \%$ and the added value of tertiary industry was 2351.80 billion yuan, with an increase of $9.6 \%$. The proportion of the three industries was 6.3:50.2:43.5. In 2012, the total output value of Shandong province reached 
5001.32 billion yuan, achieving a $9.8 \%$ growth compared with that of 2011, among which the added value of primary industry was 428.17 billion yuan, with an increase of $4.7 \%$, the added value of second industry was 2573.57 billion yuan, with an increase of $10.5 \%$ and the added value of tertiary industry was 1999.58 billion yuan, with an increase of $9.8 \%$. The proportion of the three industries was 8.6:51.4:40.

\section{B. Employment structure}

In 2012, the whole amount of employment in towns increased to 12.66 million, among which the employment amount in primary industry accounts for $33.6 \%$, the amount in second industry accounts for $30.3 \%$ and the amount in tertiary industry accounts for $36.1 \%$. From the proportion of employment in three industries, we can obviously see that the employment proportion in our country is much lower than the general level of $60 \%-75 \%$ in developed countries as well as the average level of $30 \%-45 \%$ in developing countries. The total employment amount in China was 767.04 million in 2012, including 257.73 million in primary industry, 232.41 million in second industry and 276.90 million in tertiary industry. The total employment amount in Hebei province was 40.8574 million, including 14.2627 million in primary industry, 14.0079 million in second industry and 12.5868 million in tertiary industry. The total employment amount in Guangdong province was 59.6595 million, including 14.1838 million in primary industry, 25.0969 million in second industry and 20.3788 million in tertiary industry. The total employment amount in Jiangsu province was 47.5953 million, including 9.8998 million in primary industry, 20.3232 million in second industry and 17.3723 million in tertiary industry. The total employment amount in Shandong province was 65.543 million, including 21.68 million in primary industry, 22.452 million in second industry and 21.411 million in tertiary industry.

\section{PROBLEMS IN THE PROCESS OF INDUSTRIAL STRUCTURE ADJUSTMENT IN HEBEI PROVINCE}

On basis of the comparative analysis in Part one, we can conclude that the output value structure proportion in Hebei province has improved compared with that in 2011, with all industries achieving growth while the tertiary industry experiencing a faster increase. However, compared with national output value growth rate, the total value is relatively large and the growth rate of second industry is high while that of primary and tertiary industries falls behind the national level. In addition, the output value of Guangdong, Jiangsu and Shandong in 2012 ranks top three in the country. In comparison, there is still a gap in growth rate between Hebei province and these three provinces, which is not very large. But the difference in absolute value of growth is so obvious that the primary industry owns a relatively high growth value while the value in second and tertiary industries is far behind that of the three provinces. In terms of employment amount, the amount in Hebei is much lower than that of the three provinces. In addition, the employment amount in the three industries in Hebei remains almost the same, while in other three provinces, employment amount is relatively lower in primary industry and higher in second and tertiary industries. So we can see that in more developed areas, the employment amount in second and tertiary industries is also higher. As a consequence, although the industrial structure in Hebei province is optimizing and upgrading continuously, compared with developed provinces, there are still many problems as following:

\section{A. Extensive economic growth mode}

Hebei province is located in the Beijing and Tianjin areas with a superior geographical advantage. But for many years, it has been focusing on the development of heavy industry which is still of low level and high energy consumption. In recent two years, the environmental pollution becomes more and more serious that the foggy and hazed weather in BeijingTianjin-Hebei region tends to be severer. The disadvantages of such extensive economic growth mode at the expense of energy and environment gradually emerge. Therefore, how to promote the transference of economic growth mode to reduce energy consumption and pollution has become one of the most urgent problems to be solved in economic development of Hebei.

\section{B. Low product grade and industrial structure optimization level}

In product structure, primary varieties and labor-intensive varieties occupies a larger proportion while the amount of deep processing and high quality varieties which are highly demanded in the market is relatively small. Among 260 national most competitive goods, only three of them come from Hebei, with an output value rate of new products of merely $3 \%$, which is $2.1 \%$ lower than the national level. In addition, in primary industry, the planting proportion is too large, accounting for $58.8 \%$ of the total output value of farming, forestry, animal husbandry and fishery. In second industry, the proportion of mining and raw material industries accounts for $64.5 \%$ while electronics and telecommunications manufacturing industry occupies only $0.7 \%$ of the added values of national-level enterprises. The overall level of second industry is not high. The development of the emerging service industry is slow, with weak driving force to economic growth, leading to the overall low competitiveness, small scale of main enterprises, low intensification level and lack of stimulation in economic growth.

\section{Low level of talents and technology}

Hebei Talent Development Report in 2012 has revealed a total talent amount of 5.0667 million in Hebei, an increase of $4.47 \%$ in comparison. The talent density continued to grow and reached $10.79 \%$ in 2012 , an increase of $0.53 \%$ in comparison. Great improvement has been made compared with the previous data, but the gap is still obvious in comparison with developed provinces like Guangdong and Jiangsu. In addition, high level talents with high skills are lacked. Technology and talent play an important role in adjusting industrial structure. In the gathering place of traditional industries, the economic growth is considerable if reform is made with specific skills. There are not enough senior experts, academic leader and engineering technical experts in Hebei province, which is disadvantageous for the cooperation between professional leading public relations and subjects, seriously influencing the cultivation of new economic growth of Hebei province. The talent structure is 
also not rational including academic structure, professional title structure, industrial structure, department structure, and professional structure. A large number of professional technical talents are concentrated in second industry while talents in primary and tertiary industries are insufficient. The proportion of professional technical talents specializing in scientific research on agricultural production, comprehensive technical services, and finance is a little low.

\section{Development lagging of service industry}

Seen from the development process of the world, the proportion of service industry in economic total amount is increasing. In developed countries, the proportion of service industry reaches above $70 \%$ which is much higher than the average level of developing countries. The proportion of our country is lower than developed countries while that of Hebei province is even lower than the national level. In addition, the inner structure of Hebei service industry still focuses on traditional industries such as wholesale, retail, transportation, storage and postal industries, resident service and other education service industries. New type of service industries which is adaptable to market demand and economic development (for example finance and insurance, real estate brokers and agents, property management industry, tourism industry, the advertising industry, consulting industry, home services industry, etc.) still need further development.

\section{MEASURES TAKEN TO OPTIMIZE THE INDUSTRIAL STRUCTURE IN HEBEI PROVINCE}

The notice of " the twelfth five-year" development plan issued by the People's Government of Hebei province has proposed its goal of industrial structure adjustment: during the next five years, the added value in service industry aims to achieve an average increase of above $10 \%$ per year and exceed 1000 billion yuan in 2015, with 15 thousand yuan per capita; the proportion of added value in service industry aims to reach $38 \%$ while the proportion of employees in service industry reaches above $30 \%$. The density of service industry obviously enlarges and its scale and level have an obvious improvement, forming a industrial structure focusing on service economy in cities with certain conditions such as Shijiazhuang. To achieve the optimization of internal structure, the incorporation between producer service industry and advanced manufacturing industry and the improvement of technological content and standardization degree of life service industry. Modern service industry which focuses on modern logistics, culture, tourism and finance takes the place of manufacturing industry of iron and steel, petro-chemistry and equipment, and becomes a new strategic support industry. During the "twelfth five-year", the added value in modern logistics industry aims to achieve an average increase of about $20 \%$. In 2015, the added value in cultural and financial industries aims to account for $4 \%$ of the total output value with a tourism income of 200 billion yuan. To perfect the service function by means of further improvement of the urban-rural public service system and diversifying modern service industry forms and products categories, thus developing a number of advantageous enterprises with independent intellectual property rights and well-known brands, introducing in numerous service industry gathering zones known to the world and significantly enhancing the competitiveness and influence. To realize this goal, we need to start from the following aspects:

\section{A. Enhance fundamental position of agriculture and transfer economic growth mode}

Enhance and strengthen the fundamental position of agriculture to promote overall development of the rural economy. The government always attaches primary importance to agriculture in developing domestic economy, and ensure the sustainable and stable development of agriculture on basis of increasing overall quality and benefit, by means of adding agricultural input to reduce farmers' burden and enhancing the support to agriculture. Under the premise of keeping current food production capacity, guided by market and taking farmers' revenue increase as the goal, the government vigorously develop economic crops with high quality and high efficiency as well as high quality special grain crops to adjust and optimize the planting structure; it accelerate the development of animal husbandry to adjust and optimize the agricultural structure. The government actively adjusts rural economic structure, strengthens the building of rural infrastructure to help the poor out of poverty, deepens rural reform, stabilizes double management system which is based on household contractual management with combination of centralization and decentralization, actively explores land operation rights transfer system reform and develops various kinds of moderate-scale operation. To realize the construction of agricultural industrialization, peasant professionalism and rural informatization, efforts must be made to improve total agricultural productivity, realize the transfer of agricultural economic mode from extensive to intensive, and enhance the comprehensive efficiency of technological progress, agricultural scale management and organizational innovation.

\section{B. Improve products grade and optimize industrial structure}

Speed up the strategic adjustment of industrial structure to promote the optimization and upgrading of industrial structure. Make full use of advantages to promote superior resources transformation and deep processing, extend product chains, cultivate and strengthen the pillar industry. During the "tenth five-year" plan, Henan has determined five pillar industries including the food industry focusing on the deep processing of food, animal by-products and fruits, the non-ferrous metals industry focusing on national aluminum industry base construction, coal chemical industry and petroleum chemical industry concentrating in improving resource utilization and development efficiency, machinery and equipment industry centering in electricity transmission equipments and complete equipments, and textile industry focusing on upgrading of paper, tobacco and textile products. Accelerate the speed of traditional industry transform by means of high technology and advanced applicable technology, so as to actively implement brand strategy and cultivate a number of wellknown brands and advantageous enterprises. Speed up the development of high-tech industry to conform to the technological development trend, concentrate on the cultivation of high-tech products with obvious market competitiveness and try to make electronic information and bio technology industry gradually into the new pillar industry 
in Henan. Innovate and improve industries of iron and steel, building materials and pharmaceutical, positively develop labor-intensive processing industries, and increase market share and exchange capacity. Try to stimulate industrialization through informationization and try to promote informationization through industrialization, thus achieving great-leap-forward development.

Develop high-tech industry and attach great importance to port economy. Current economy in Hebei is resource-based with more raw material industries and primary products and less high value added products. Therefore, it is the necessary choice to construct a modern Hebei to accelerate high-tech industry and realize the transform from resource-based economy to innovative economy. Hebei province is around Beijing and Tianjin, where gather many high-level talents and scientific research institutions, providing a largest advantage for Hebei in developing high-tech industry. At present, due to the lack of platform connecting the technological achievement transfer with Beijing and Tianjin, many technologies fail to settle down in Hebei. As a consequence, to take the advantage of Beijing and Tianjin in developing Hebei's high-tech industry, it is necessary to build such a platform and provide conditions for high-tech achievement transference. Take time to plan the development of high-tech industry in Hebei province to create conditions for industrial structure adjustment. Concentrate on the cultivation and support of development of port industry. Further strengthen the construction of four harbors including Caofeidian deepwater harbor, Qinhuangdao Harbor, Huanghua Harbor and Jingtang Harbor, and form a harbor group in Hebei, thus achieving functional complementation and fully playing the roles of harbors. In addition, more efforts are needed in comprehensive development of the harbor functions, for example, to form and develop harbor industry chains by vigorously developing warehousing, ship repairing, inside and outside processing industries, foreign ship oil supply bases and seaborne logistics centers.

\section{Optimize talent environment and improve talent and technology level}

In order to realize the goal of becoming a strong province with talents and promote the innovative construction, it is significant for Hebei province to seize key talent project construction, implement talent development programs, actively and steadily push the construction of "home to talents", focus on the "flexible introduction" of talents from Beijing, Tianjin and overseas, emphasize on the cultivation and development of various talents including high-level innovative talents, rural practical talents, skilled talents, new industrialization talents, and talents in modern service industry, city construction, private economy development and coastal development, and make efforts to build a talent team with large scale, reasonable structure and high quality, aiming to possessing more than eight million talents in the whole province at the end of the "twelfth five-year" plan. Speed up the construction of a technological innovation system taking enterprises as focus while taking market as guidance which combines production, study and research, so as to increase the proportion of $R \& D$ funds input in total output value. Enhance the training of agricultural technology talents in grass-roots, transfer appointment mechanism of talent, improve welfare of talents, and in particular, bring in high-tech talents and improve talent quantity and quality in tertiary industry. At the same time, prevent talent outflow in second industry.

\section{Fully develop service industry and accelerate the marketization, industrialization and socialization process of service industry.}

Focus on the development of modern service industry with strong growth potential and large employment capacity, broaden the area of service, optimize service structure, and improve service level to significantly increase the proportion of added value of service industry in gross domestic production as well as the proportion of employees in the whole employment in the society. There are several ways to achieve this goal. First is to develop tourism with great efforts. By making use of Henan's advantages of rich tourist resources and good location, implement famous brand strategy, aiming to make Henan a cultural and tourism province as soon as possible and develop tourism industry into a pillar industry. Make overall plans. While further strengthening the protection of historical and cultural resources, actively develop tourist resources focusing on humanism and natural landscape, hoping to gain an annual average growth of $12 \%$ of total tourism revenues in the "tenth five-year" period. In 2008, the total revenues reached 63 billion yuan, accounting for more than $8 \%$ of the provincial GDP. Second is to improve development level. Under the premise of efficiently preventing financial risks, develop financial and insurance industries actively. Strive to develop service industry in urban communities, promote the healthy development of industries such as culture and entertainment, health care, nursery and rest home, employment agency and so on. Actively develop social intermediary services like accounting, laws, prices and consulting, so as to adapt to the transfer of rural labor to towns and meet the socialization need of efficient logistics service. Build apartment-style houses of multi specifications and grades to satisfy various consumers, vigorously develop the trade of commodity circulation, develop and form all kinds of professional markets and form both national and regional commodity logistics centers.

\section{REFERENCES:}

[1] Ma, G. Q. (2000, October). Development of Industrial Economics in Western Countries and its Construction in China. Foreign Economics and Geography.

[2] Han, D. T., \& Yang, Y. (2008, April). Economic Structure Adjustment and Growth Mode Transfer-Thoughts on Several Problems in Liaoning Economic Development. Social Science Journal.

[3] National Bureau of Statistics. China Statistical Yearbook in 2013. Beijing: China Statistics Press.

[4] Liu, K. (2012, April). Doctoral Dissertation of Target and Strategic Research on China's Economic Structure Adjustment in Post Financial Crisis Era.

[5] Xia, J. C., \& Yao, Z. Q. (2013, May). Foreign Investment and Economic Structure Adjustment in Service Industry: An Empirical Study Based on China. Journal of Nanjing University (Philosophy. Humanity. Social Science Ed.).

[6] Feng, J. J. (2010, May). Economic Development Mode Transfer and Economic Structure Adjustment. Research on Finance and Accounting. 